\title{
Contratación entre cónyuges: desterrando viejos mitos sobre la prohibición del artículo 312 del Código Civil( ${ }^{*}\left(\left(^{*}\right)\right.$
}

\author{
Interspousal contracts: banishing old myths about the prohibition of article \\ 312 of Civil Code
}

\author{
Romina Santillán Santa Cruz ${ }^{(* *)}$ \\ Universidad de Zaragoza (Zaragoza, España)
}

\begin{abstract}
Resumen: La regulación de la contratación entre cónyuges puede variar en cada ordenamiento jurídico dependiendo del modelo de gestión del patrimonio conyugal adoptado por este último. Algunos Derechos comparados, como el español, admiten una amplia libertad de contratación entre cónyuges, pues consideran que el matrimonio no tiene por qué limitar su libertad de contratar. En cambio, el Derecho peruano prohíbe a los cónyuges contratar entre sí sobre sus bienes sociales. Pero este impedimento requiere una interpretación restrictiva para conocer el real alcance del artículo 312 CC, ya que la prohibición prevista en esta norma no parece aplicarse a los bienes propios de cada cónyuge. De ser así, incluso podría plantearse el uso de los denominados pactos de atribución de ganancialidad a los bienes propios, que reciben regulación en ordenamientos extranjeros. Por tales razones, este trabajo ofrece un estudio de la contratación entre cónyuges en Perú para conocer su estricto ámbito de aplicación, los fundamentos y la finalidad de la mencionada prohibición. Se realiza, así mismo, un breve análisis de los efectos prácticos que podrían desencadenarse a causa de la nueva interpretación que quiero proponer y que está centrada en el concepto de "bienes de la sociedad" contenido en el artículo 312 CC.
\end{abstract}

Palabras clave: Contratación entre cónyuges - Sociedad de gananciales - Bienes sociales - Bienes propios - Pactos de atribución de ganancialidad a los bienes propios.

\begin{abstract}
The regulation of recruitment between spouses may vary in each legal system depending on the model of management of marital property adopted by the latter. Some comparative Laws, such as Spanish Law, allow for broad freedom of recruitment between spouses, considering that marriage should not limit their freedom to contract. Instead, Peruvian Law prohibits spouses to contract each other with respect of their common property. But this impediment requires a restrictive interpretation for knowing the real scope of article 312 of Civil Code, since the prohibition provided in this rule does not seem to apply to the personal property of each spouse. If so, the so-called agreements of attribution of common nature to personal property, regulated in foreign legal systems,
\end{abstract}

(*) Nota del Editor: este artículo fue recibido el 3 de mayo de 2020 y su publicación fue aprobada el 14 de mayo de 2020.

$\left({ }^{* *}\right)$ Este trabajo ha sido realizado en el marco del Grupo Consolidado de Investigación del Gobierno de Aragón lus Familiae, IP. Carlos Martínez de Aguirre Aldaz. Forma parte de la investigación doctoral que ha llevado a cabo la autora en la Universidad de Zaragoza, cuyo título es "La legitimación de los cónyuges para disponer de los bienes comunes bajo régimen de sociedad de gananciales en el Derecho peruano. Estudio comparado con el Derecho español”. Así mismo, el presente trabajo tiene su antecedente en el artículo "Pactos de atribución de ganancialidad o de privatividad a los bienes bajo un régimen de gananciales. Apuntes de Derecho español y peruano", publicado en Revista Boliviana de Derecho, 2020, núm. 29, p. 488-498; este constituyó tan solo una primera y breve aproximación al tema que aquí se aborda ampliamente.

${ }^{(* * *}$ Investigadora contratada en la Facultad de Derecho de la Universidad de Zaragoza (España). Doctora en Derecho y Master en Especialización e Investigación en Derecho, con mención en Derecho de la Familia y de la Persona, por la Universidad de Zaragoza (España). Abogada por la Universidad Católica Santo Toribio de Mogrovejo (Perú). Código ORCID: 0000-0003-1748-6062. Correo electrónico: rsantillan@unizar.es 
could also be used in Peruvian Law. For these reasons, this work offers a study about the recruitment between spouses in Peru in order to know its strict scope, grounds and purpose of the prohibition mentioned. Similarly, I make a brief analysis of the practical effects that would be presented because of the new interpretation that I would like to propose and which is centred on the concept of "property of society" contained in article 312 of Civil Code.

Keywords: Inters pousal contracts - Community of property Common property - Personal property - Agreement of attribution of common nature to personal property.

\section{Introducción}

La regulación de la contratación entre cónyuges puede variar en cada ordenamiento jurídico dependiendo del modelo de gestión del patrimonio conyugal adoptado por este último. Algunos Derechos comparados, como el español común, admiten una amplia libertad de contratación entre cónyuges, pues consideran que el matrimonio no debe suponer un límite a su libertad de contratar. Con lo cual han sentado las bases para hablar de un nuevo contractualismo en el Derecho de Familia (Gete-Alonso, 1990, p. 900). En cambio, el Derecho peruano prohíbe a los cónyuges contratar entre sí sobre sus bienes sociales. Lo cual despierta el interés por conocer y valorar las razones que justificarían que, en tiempos actuales, preceptos que son restrictivos de la autonomía privada de los cónyuges y de su libertad para contratar entre sí, sigan teniendo acogida.

La prohibición de contratar entre cónyuges está prevista en el artículo 312 del Código Civil peruano (en adelante, CC). Este precepto requiere una interpretación restrictiva para desentrañar su real alcance, pues la prohibición que establece esta norma no parece extenderse a los bienes propios de cada cónyuge. De ser así, incluso podría plantearse el uso de los denominados pactos de atribución de ganancialidad a los bienes propios, que reciben una expresa regulación en algunos ordenamientos extranjeros ${ }^{(1)}$. Estos pactos constituyen un mecanismo por el cual los cónyuges, de común acuerdo, deciden atribuir naturaleza común a un bien propio. Es decir, en estos opera la autonomía de la voluntad de los cónyuges para alterar la naturaleza que, conforme a los criterios legales de determinación, el bien había de tener (Gutiérrez Barrenengoa, 2002).

Bajo este escenario, el propósito del presente artículo es ofrecer un estudio sistemático y teleológico de la contratación entre cónyuges en Perú para conocer su estricto ámbito de aplicación, los fundamentos y la finalidad de la mencionada prohibición. En ocasiones me remitiré a la doctrina y la legislación españolas para centrar y reconducir el desarrollo del objeto de estudio, como sucede cuando analizo la libertad de contratación entre cónyuges y el mecanismo de la atribución voluntaria de ganancialidad a los bienes, cuyos fundamentos y doctrina luego confronto para resolver la cuestión en Derecho peruano. Del mismo modo, se realiza un breve análisis de los efectos prácticos que podrían desencadenarse a causa de la nueva interpretación que vengo a proponer y que está centrada en el concepto de "bienes de la sociedad" contenido en el artículo 312 CC. Solo deconstruyendo este precepto a sus elementos conformadores podrá determinarse su verdadero sentido.

\section{2. Ámbito de la contratación entre cónyuges a causa de "una prohibición": deconstruyendo el artículo 312 CC}

En Perú, la cuestión relativa a la contratación entre cónyuges recibe su regulación en el artículo 312 CC. Este precepto se sitúa dentro del Capítulo Segundo sobre "Sociedad de Gananciales", que, a su vez, se halla en el Título III sobre "Régimen Patrimonial", ubicado en la Sección Segunda que corresponde a la "Sociedad Conyugal", la cual se encuentra, al propio tiempo, dentro del Libro III del CC, regulador del "Derecho de Familia". Prescribe las reglas de juego a aplicarse en los contratos entre cónyuges, y en cuyo ámbito, como señala textualmente la norma, "los cónyuges no pueden celebrar contratos entre sí respecto de los bienes de la sociedad".

La doctrina no ha sabido dar una explicación clara y satisfactoria al problema que plantea la adecuada dilucidación del ámbito de aplicación del artículo 312 CC,

(1) Como el Derecho español común, que luego se analiza con detalle. De otra parte, hay quien considera que el Derecho argentino, con el nuevo Código Civil y Comercial de la Nación, habría admitido con amplitud los contratos entre cónyuges, pudiendo haber "transferencia de propiedad, a título oneroso o gratuito, entre cónyuges, alterando así la calificación de los bienes en el régimen de comunidad, con consecuencias fundamentalmente sucesorias" (Roveda, 2015, p. 105). 
como tendremos ocasión de ver más adelante. Una lectura segmentada de este dispositivo legal nos llevaría a creer que la expresión "bienes de la sociedad" hace alusión a todos los bienes que integran la sociedad de gananciales, es decir, los bienes propios y los bienes sociales. Incluso, en virtud del encabezado que se le asigna en el CC, se podría reconocer genéricamente que aquella es la norma reguladora de la "prohibición de contratos entre cónyuges"(2). Por tanto, si la interpretación de la norma obedeciera a un sentido puramente gramatical, siguiendo el proceso mental indicado, los cónyuges simplemente no podrían contratar entre sí. Pero esto no es lo que parece querer expresar el precepto. Aunado a lo anterior está también el problema de la escasa bibliografía sobre la materia. De ahí que su interpretación requiera de algunas pautas directrices o líneas maestras que orienten debidamente, y con paso firme, un trabajo hermenéutico capaz de obtener el verdadero sentido de la norma.

Como punto de partida para este análisis hay que poner énfasis en el estricto contenido del artículo 312 CC. Este precepto contiene una prohibición impuesta a los cónyuges respecto de su libertad de contratar entre sí sobre determinados bienes, razón por la que no debe realizarse una interpretación extensiva del dispositivo legal en cuestión. Una interpretación bajo este criterio tornaría arbitraria la lectura de la norma y, con ello, su supuesto de aplicación sería más restrictivo de lo que, a juicio de algunos, entre quienes me incluyo, ya es (Gutiérrez Camacho, 2007a, p. 242-244). Lo que se quiere evitar es la injustificada ampliación de una expresa e inteligible prohibición a un ámbito que no se desprende ni del propio contenido del artículo 312 CC ni, mucho menos, de su ubicación sistemática dentro del Código. Pese a ello, caben diversas interpretaciones, como ahora veremos.

Hay quien considera que el citado artículo prohíbe a los cónyuges celebrar contratos entre sí respecto de los bienes de la sociedad, salvo cuando se trata del otorgamiento de poderes, con la única finalidad de proteger a los terceros frente a posibles colusiones entre los cónyuges; disposición prohibitiva que, según esta misma opinión, también suele aplicarse en caso de separación de patrimonios, aunque no exista norma expresa al respecto (Aguilar Llanos, 2008, p. 157) ni sea ese el sentido recogido en la redacción del artículo $312 \mathrm{CC}$, que forma parte del conjunto de reglas que rigen la sociedad de gananciales.

Desde otra perspectiva doctrinal, si bien el texto del referido artículo contiene la regla general de que los cónyuges no pueden contratar sobre bienes del patrimonio conyugal, esto no significa que la contratación entre esposos se halle totalmente proscrita en Derecho peruano, pues no existe como tal impedimento legal para que los cónyuges celebren contratos sobre los bienes propios u otros contratos que no comprometan los bienes sociales (Gutiérrez Camacho, 2007a, p. 242). Defendiendo, al propio tiempo, que no existe impedimento alguno para que los cónyuges que optaron por una separación de patrimonios celebren todo tipo de contratos (2007a, p. 242-243).

En mi opinión, la solución al problema se encuentra en la interpretación sistemática de los artículos 301, 310, 312 y 315 CC (Santillán Santa Cruz, 2020). De acuerdo con el artículo301 CC, "en el régimen de sociedad de gananciales puede haber bienes propios de cada cónyuge y bienes de la sociedad", donde estos últimos no serían sino los bienes comunes a los cónyuges. La denominación más precisa para los bienes de la sociedad es posible encontrarla en los artículos 310 y 315 CC, que utilizan, de modo explícito, el concepto de "bienes sociales"; preceptos con que el legislador peruano parecería haber querido zanjar cualquier posible confusión en la interpretación de la expresión "bienes de la sociedad". Esta expresión no se estaría refiriendo a todos los bienes que integran la sociedad de gananciales, sino en estricto a los bienes que se hacen comunes de los cónyuges y sobre los que no se tienen partes alícuotas (Varsi Rospigliosi, 2012; Castro Pérez Treviño, 2010; y, Aguilar Llanos, 2008). Y si todo ello se armoniza con lo dispuesto en el artículo 312 CC, apelando a la coherencia del sistema y al tenor literal de esta norma, "lo que no pueden hacer los cónyuges durante la vigencia del régimen de gananciales es contratar entre sí sobre los bienes sociales, mas esta limitación no alcanza a una eventual contratación respecto de sus bienes propios" (Santillán Santa Cruz, 2020, p. 495).

Traducida en estos términos la previsión del artículo 312 CC, resulta también del análisis que los bienes sociales solo existen en el ámbito de la sociedad de gananciales y no en el de la separación de patrimonios, por lo que la prohibición expresada en el citado

(2) Vid. el rótulo legal que encabeza la citada norma en la versión del CC que aparece en el Portal Oficial del Sistema Peruano de Información Jurídica del Ministerio de Justicia y Derechos Humanos (16a ed., marzo 2015). Disponible en http://spij.minjus.gob.pe/ notificacion/guias/CODIGO-CIVIL.pdf (última consulta: 2/5/2020). 
artículo no sería posible extenderla a los cónyuges sujetos a este último régimen patrimonial.

"A esta conclusión se arriba, así mismo, tras repararse en la ubicación sistemática que el referido precepto recibe en el Código Civil peruano: se encuentra dentro del marco normativo de la sociedad de gananciales y, como se ha podido ver, solo es de aplicación en las relaciones económico-patrimoniales que entablen los cónyuges sujetos a tal régimen. Constante sociedad de gananciales, los cónyuges no pueden contratar entre sí respecto de los bienes de la sociedad" (Santillán Santa Cruz, 2020, p. 496).

Recapitulando, vemos entonces que para determinar el alcance del precepto bajo análisis se deben tener presentes dos cuestiones relevantes.

La primera de ellas está relacionada con la ubicación de la norma, ya que, en la estructura del CC, el artículo 312 se sitúa bajo el epígrafe de la "sociedad de gananciales", y ello permite advertir que esta regla fue dada para ordenar el mencionado régimen, no resultando exigible, por tanto, en el marco de una separación de patrimonios.

La segunda cuestión guarda conexión con la literalidad del precepto, pues se advierte en él una explícita referencia a los "los bienes de la sociedad", que es en relación con los cuales "los cónyuges no pueden celebrar contratos entre sí". Esto viene a reafirmar que la antes aludida es una norma propia del régimen de gananciales, que no resulta de aplicación, bajo ningún sentido, al régimen de separación de patrimonios (Gutiérrez Camacho, 2007a; y, Castillo Freyre, 2015), a diferencia de lo que señala alguna opinión doctrinal, incluso cuando reconoce la inexistencia de norma prohibitiva al respecto (Aguilar Llanos, 2008), como antes se vio. La explicación es sencilla: en un régimen de separación de patrimonios no hay bienes sociales $\mathrm{y}$, en consecuencia, no tendría por qué afectarle lo dispuesto en el artículo 312 CC.

Con las indicaciones que preceden queda claro que, en materia de contratación entre cónyuges, cuyo matrimonio se encuentra sujeto al régimen de gananciales, rige lo dispuesto por el artículo 312 CC: "Los cónyuges no pueden celebrar contratos entre sí respecto de los bienes de la sociedad". Este artículo, como apunta mayoritariamente la doctrina, aunque sin profundizar demasiado en los aspectos antes puestos de relieve, prohíbe a los cónyuges celebrar entre sí contratos que comprometan los bienes de la sociedad (Castillo Freyre, 2015; Varsi Rospigliosi, 2012; Castro Pérez Treviño, 2010; y, Aguilar Llanos, 2008). La norma no dice que la contratación entre cónyuges se encuentre totalmente proscrita en Derecho peruano. El impedimento legal se reserva únicamente para los bienes sociales. No existe, por tanto, impedimento legal alguno para que los cónyuges celebren contratos sobre sus bienes propios o realicen cualesquiera otros contratos que no afecten los bienes sociales (Gutiérrez Camacho, 2007a, p. 242), como se ha visto con anterioridad.

La jurisprudencia peruana también se ha pronunciado brevemente sobre el particular ${ }^{(3)}$, aunque existen, en general, escasas referencias al respecto. Así, de acuerdo con el criterio fijado por la Corte Suprema: "el régimen de sociedad de gananciales está regulado por normas denominadas de orden público, estableciéndose limitaciones de orden contractual entre los cónyuges" (Cas. N 95-1996-Ica, El Peruano, 30 diciembre 1997, 224). Como se puede ver, aunque no se haya indicado expresamente que las "limitaciones" recaen solo sobre los bienes sociales, sí se advierte de la doctrina jurisprudencial que la denominada "limitación de orden contractual" estaría dirigida únicamente a los cónyuges cuyo matrimonio quedó sometido a un régimen patrimonial de sociedad de gananciales. Lo cual, analizado al amparo del estricto tenor literal del artículo 312 CC, hace posible apreciar que la prohibición contractual a los cónyuges constante sociedad de gananciales tiene alcance únicamente "respecto de los bienes de la sociedad", mas no sobre los bienes propios de cada cónyuge.

\section{Libertad de pactos y contratos entre cónyuges en el Derecho comparado}

A diferencia de lo que sucede en Derecho peruano, el Derecho español común se inspira en el principio de libertad de contratación entre cónyuges (Garrido de Palma, 2001; y, Peña Bernaldo de Quirós, 1989). El artículo 1.323 del Código Civil español (en adelante, CC esp.) regula con la suficiente extensión este principio, así como el de autonomía patrimonial entre cónyuges (Garrido de Palma, 2001, p. 220), que aparece en la parte inicial de dicho precepto y que se verá más adelante con mayor detalle, y lo hace de acuerdo con el siguiente tenor: "Los cónyuges podrán transmitirse por cualquier título bienes y derechos y celebrar entre sí toda clase de contratos".

(3) He querido dejar este argumento de autoridad para el final con el único objeto de evitar que condicione mis propios razonamientos. De este modo, la línea jurisprudencial trazada por la Corte Suprema solo viene a reforzar el análisis previamente desarrollado. 
No obstante, como se puede advertir de la experiencia y evolución histórica de este Derecho extranjero, la contratación entre cónyuges no siempre estuvo concebida en los términos que le dispensa la regulación vigente. Tanto es así, que la derogada legislación civil española no dista mucho de la actual legislación civil peruana, ya que antes de la reforma del CC esp. operada en 1981, los cónyuges tenían prohibido contratar entre sí en determinados supuestos y, además, la contratación entre ellos tenía un mínimo alcance: no podían venderse bienes recíprocamente sino solo en caso de haber pactado separación de bienes o cuando esta separación se hubiese producido por disposición judicial (Pérez Vallejo, 2002, p. 141-142). Es por ello que, con la reforma introducida mediante Ley 11/1981, de 13 de mayo, el artículo 1.458 CC esp. empieza a contemplar con total amplitud que "los cónyuges podrán venderse bienes recíprocamente"; precepto último que se condice perfectamente con el recogido por el artículo 1.323 CC esp., que acabamos de ver.

Los artículos del CC esp. antes citados, como se puede observar, permiten a los cónyuges celebrar entre sí toda clase de contratos, lo que incluye la posibilidad de venderse bienes recíprocamente, con independencia del régimen matrimonial al que aquellos se encontraran sujetos. Y la razón fundamental por la que el CC esp. regula la libertad de contratación entre cónyuges en los amplios términos en que lo hace, descansa, como bien recoge la jurisprudencia del Tribunal Supremo y de la Dirección General de los Registros y del Notariado, en que: "no se puede privar a dos personas por el hecho de estar casadas
entre sí del poder de realizar los actos que a cualesquiera otras
les está permitido, toda vez que el artículo 1323 C.c. ha superado
las antiguas restricciones a la contratación entre cónyuges" [STS
18 mayo 1992 (RJ 1992, 4907) y Rs. DGRN 7 octubre 1992 (RJ
1992, 8302), 11 junio 1993 (RJ 1993, 5418) y 28 mayo 1996 (RJ
1996, 4012)].

Empero, pese a que la regla básica de libertad de contratación entre cónyuges está más que admitida y respaldada por gran parte de la doctrina académica española (Martínez de Aguirre, 2016a; Monfort Ferrero, 2011; Gutiérrez Barrenengoa, 2002; Pérez Vallejo, 2002; Garrido de Palma, 2001; Gete-Alonso, 1990; Peña Bernaldo de Quirós, 1989; y, De los Mozos, 1982), no ha faltado quien considere que:

\footnotetext{
"la ausencia de referencia a límites particulares a esta libertad de contratación, hace que la licitud y eficacia de cada contrato inter cónyuges haya de ser valorada de acuerdo con las normas generales sobre validez de los negocios jurídicos, con particular atención a aquellos actos trasmisivos que pudieran tener causa ilícita o fines defraudatorios de derechos de terceros" (Aguilar Ruiz y Pizarro Moreno, 2015, p. 113-114).
}

En un sentido semejante al anterior, a decir de otra opinión, en la medida que el artículo1.323 CC esp. es aplicable a todos los regímenes económicos, pues forma parte del llamado régimen matrimonial primario(4), bien podría utilizarse dicha libertad con fines defraudatorios y para eludir las normas imperativas que rigen sobre todo en el régimen de sociedad de gananciales (Blasco Gascó, 1997, p. 185). Siendo que, bajo la apariencia de transmisiones entre cónyuges, podrían estarse quebrantando las rígidas normas sobre modificación del régimen económico matrimonial (1997, p. 185).

Sin embargo, es poco factible que a través de la contratación entre cónyuges quede modificado de forma encubierta este régimen económico, ya que para que la modificación sea válida y eficaz frente a terceros deberá haberse constar en capitulaciones matrimoniales (Monfort Ferrero, 2011, p. 862), mismas que deben otorgarse por escritura pública, que será inscrita en el Registro Civil, así como en el Registro de la Propiedad, si los pactos afectaren a inmuebles (artículo 1.327 y $1.333 \mathrm{CC}$ esp.). En cualquier caso, la modificación de este régimen, realizada constante matrimonio, no perjudicará los derechos adquiridos por terceros, pues así lo ha dispuesto el artículo 1.317 CC esp. Ante ello, observa Lacruz y Albaladejo (1963) que la conservación de los derechos adquiridos no está condicionada al registro de los derechos o de la confianza en la apariencia, pues lo protegido es la anterioridad, es decir, el hecho de que los terceros hayan adquirido esos derechos con anterioridad a la modificación del régimen económico matrimonial (Martínez de Aguirre, 2016a, p. 226).

En virtud del principio de libertad de contratación que inspira, junto con otros principios, como el de igualdad y autonomía patrimonial, al sistema de gestión del patrimonio conyugal vigente en Derecho español común, los cónyuges podrán celebrar entre sí contratos de naturaleza onerosa,

(4) En palabras de García Cantero, este régimen matrimonial primario es el "conjunto de reglas o principios, que el legislador considera de valor general aplicable a todos los matrimonios que se celebren bajo su vigencia, y que se presentan con algún grado de obligatoriedad o vinculación (se excluyen así los meros consejos, exhortaciones o normas de conveniencia, o de buena gobernanza); normas que afectan a quienes contraen matrimonio entre sí, y que actúan fundamentalmente regulando las relaciones patrimoniales entre aquéllos y con los terceros con quienes contratan en determinadas circunstancias" (2018, p. 36). 
como son la compraventa de bienes, el reconocimiento o cesión de créditos y derechos, incluyendo los derechos inherentes a la cuota ganancial de alguno de los cónyuges [STS 19 diciembre 1997 (RJ 1997, 9110)], entre otros, hasta una constitución de sociedades [R. DGRN 13 junio 1983 (RJ 1983, 6976)]. Del mismo modo, entre cónyuges pueden celebrar contratos de naturaleza gratuita, como donaciones (vid. artículo 1.341.1 CC esp.).

Para Martínez de Aguirre (2016a), las reglas contenidas en el artículo 1.323 CC esp. se valorarían incluso innecesarias atendiendo a la propia sistemática del CC esp., pues, al haberse derogado expresamente de este cuerpo normativo todas las prohibiciones alusivas a los contratos entre cónyuges:

\begin{abstract}
"cualquier limitación a la libertad de contratación entre cónyuges debería estar legalmente establecida, y si no lo está es claro que los cónyuges pueden contratar entre sí con la amplia libertad a que se refiere el artículo. Su presencia se justifica por las limitaciones a esa libertad que existieron en el Código civil hasta la reforma de 1981. No estamos, pues, ante una norma peculiar del régimen económico matrimonial, sino ante la reafirmación de que también entre cónyuges rige la regla general de libertad de contratación. Por lo demás, el artículo1.323 Cc. debe su usual redacción a la Ley $13 / 2005$, que sustituyó la anterior mención al marido y la mujer, por la más genérica a los cónyuges" (2016a, p. 229).
\end{abstract}

Sobre la base de los argumentos anotados, se puede advertir que no existe razón alguna para limitar la libertad de los cónyuges para contratar entre sí sobre sus bienes, sean estos propios o comunes de ambos, pues la posibilidad de realizar actos defraudatorios no es una que se encuentre ínsita en la condición misma de los cónyuges, sino que tales pueden tener lugar como consecuencia de la actuación de cualquier sujeto, inmerso o no en una relación jurídico matrimonial. Las inhabilitaciones especiales dirigidas a prohibir que puedan contratar entre sí, y en interés propio, los cónyuges que han contraído matrimonio bajo un régimen de comunidad de bienes, como es la sociedad de gananciales, entrañarían por tanto cierta razón de injusticia, pues la condición de casados no comporta mayores peligros de lesión a los intereses de terceros o del propio cónyuge. Es más, para hacer frente a estos posibles peligros "no es necesario acudir a medidas específicas, sino que basta con aplicar las normas que con carácter general establecen límites en la contratación" (Clemente Meoro, 2012, p. 570).

De acuerdo con ello, como bien apunta Monfort Ferrero:

"los actos y negocios entre cónyuges están sujetos a los mecanismos correctores de la rescisión por fraude (artículo 1291 y siguientes CC)
(5), de la reducción de donaciones inoficiosas en caso de que se perjudique a los legitimarios con el contrato celebrado entre cónyuges (artículo 636 y ss. CC) o de la anulabilidad por vicios del consentimiento en caso, por ejemplo, de captación del consentimiento de un cónyuge por el otro (artículo 1300 y ss. CC)" (2011, p. 861).

Cabe, entonces, una reflexión para cerrar este apartado. Puestos en el peor de los escenarios, si las normas generales de los contratos previstas en un determinado ordenamiento no resultaran ser suficientes para mitigar los efectos de un eventual fraude, más que impedir la libre contratación entre cónyuges, lo adecuado sería, en todo caso, implementar mecanismos legales concretos $y$ efectivos que permitan hacer frente a esos posibles fraudes convenidos por los cónyuges con la intención de perjudicar a terceros acreedores; algo que no es necesario en Derecho español porque, como acabamos de ver, bastaría con recurrir a las normas generales de los contratos para combatir los riesgos que subyacen a la libertad de contratación entre cónyuges.

\section{Fundamentos y finalidad del límite a la libertad de contratar entre cónyuges en Derecho peruano}

Habiendo desarrollado los fundamentos que han llevado al Derecho español común a regular con gran extensión la libertad de contratación entre cónyuges, a continuación, se analizan los fundamentos y la finalidad del límite a la libertad de contratar entre cónyuges establecido en Derecho peruano. El objeto central de este apartado es conocer y valorar las razones que justificarían que, en tiempos actuales, preceptos que son restrictivos de la autonomía privada de los cónyuges y de su libertad para contratar entre sí, sigan teniendo acogida en el último Derecho citado.

Autorizada doctrina ha señalado que la prohibición contenida en el artículo 312 CC fue prevista con la finalidad de proteger a

(5) Por ejemplo, el artículo 1.291 CC esp. establece que son rescindibles los contratos "celebrados en fraude de acreedores, cuando éstos no puedan de otro modo cobrar lo que se les deba". Y conforme a lo dispuesto en el artículo 1.298 CC esp., "el que hubiese adquirido de mala fe las cosas enajenadas en fraude de acreedores, deberá indemnizar a éstos de los daños y perjuicios que la enajenación les hubiese ocasionado, siempre que por cualquier causa le fuera imposible devolverlas". 
los terceros frente a posibles colusiones entre los cónyuges (Aguilar Llanos, 2008, p. 157). También con el objeto de evitar el eventual aprovechamiento de uno de los cónyuges en perjuicio del cónyuge menos involucrado en la gestión de los bienes o con menos entendimiento en el asunto (Gutiérrez Camacho, 2007a, p. 243). Otra de las razones que se señala para justificar el precepto en cuestión es que los cónyuges no pueden contratar entre sí respecto del patrimonio social, porque en materia patrimonial ambos (entiéndase los cónyuges y el patrimonio social) constituyen una sola parte, una sola voluntad, y para la celebración de un contrato se necesitan como mínimo dos voluntades (Gutiérrez Camacho, 2007a, p. 243). De las razones expresadas, claramente esta última es la que resulta menos sostenible, de acuerdo con la asentada doctrina que desvirtúa cualquier posible fusión entre la sociedad de gananciales y los cónyuges: el patrimonio social es un patrimonio autónomo integrado por todos los bienes que hubiesen adquirido onerosamente los cónyuges durante el matrimonio y que tienen legalmente la condición de bienes sociales (Varsi Rospigliosi, 2012, p. 148-152; Castro Pérez Treviño, 2010, p. 115-117; y, Aguilar Llanos, 2008, p. 146-147).

Lo anterior permite advertir que, en Derecho peruano, la contratación entre cónyuges sobre sus bienes sociales estaría siendo prohibida en virtud de una afincada tradición normativa que está pensada en favor de los terceros (aun cuando ello comporte una restricción a las libertades de los cónyuges en la esfera contractual) y del cónyuge débil ante la gestión de los bienes, una situación que ha tratado de paliarse con el establecimiento de una igualdad legal entre cónyuges (vid. artículo $234 \mathrm{CC}$ ), que actualmente constituye principio rector del Derecho familiar peruano (Plácido Vilcachagua, 2016). Además, de acuerdo con las razones dadas por la doctrina, dicha prohibición presupone que el patrimonio social y los cónyuges se fusionan formando un único sujeto, no pudiendo, por ende, contratar consigo mismo, algo que no se ajusta al espíritu normativo del CC, ya que el patrimonio común, como antes se ha visto, no es sujeto de derechos, sino que pertenece conjuntamente a los cónyuges; no se confunde con estos porque no son sujetos susceptibles de confusión ${ }^{(6)}$, ni tampoco con sus patrimonios privativos.

Ahora bien, si el asunto se analizara con una perspectiva eminentemente práctica, dejando de lado esas cuestiones interpretativas y teóricas que se han destacado y que permiten desvelar el verdadero objeto de la norma, se correría un claro riesgo de que la limitación al derecho de los cónyuges a contratar entre sí sobre sus bienes sociales, que es lo que realmente establece el artículo 312 CC, termine siendo traducida bajo un criterio equívoco y absoluto que asocie, sin más, matrimonio sometido a régimen de gananciales con restricción a la libertad de contratar de los cónyuges, cuando esto no se ajusta al verdadero sentido de la norma. Lo cual, en su versión más extremada y superficial, podría recibir incluso una lectura totalmente segmentada y errónea: "el matrimonio limita la libertad de contratar de los cónyuges entre sí"; algo que tampoco refleja el espíritu del CC.

Aun con la problemática que puede plantear el artículo $312 \mathrm{CC}$, lo cierto es que este precepto no prohíbe in límine la libertad de contratar de los cónyuges, sino solo la celebración de contratos entre sí sobre sus bienes sociales, quedando a salvo la posibilidad de contratar sobre sus bienes propios o de terceros (Santillán Santa Cruz, 2020 , p. 495). En la misma medida, pueden celebrar entre ellos cualesquiera otros contratos $^{(7)}$ siempre que estos no involucren sus bienes sociales ni interesen sobre estos una patrimonialidad directa (Varsi Rospigliosi, 2012, p. 221). No se está, por tanto, frente a una prohibición total ni absoluta; es parcial y relativa (Varsi Rospigliosi, 2012, p. 221), pues en los supuestos antes detallados sería perfectamente legal y viable la contratación entre cónyuges durante la vigencia de la sociedad de gananciales.

Pese a esta forma de entender la cuestión, alguna voz acreditada en la doctrina peruana ha sostenido que el artículo 312 CC limita severamente el derecho de contratar de los cónyuges, cuando haberse casado no debería significar para ellos una renuncia al principal instrumento legal que puede permitir su desarrollo económico: el contrato (Gutiérrez Camacho, 2007a, p. 242-244). A esto se agrega que la posibilidad de contratación

(6) Aun cuando existan imprecisiones técnicas en la redacción del segundo párrafo del artículo65 del Código Procesal Civil: "La sociedad conyugal y otros patrimonios autónomos son representados por cualquiera de sus partícipes, si son demandantes. (...)", que han llevado a algún autor a sostener que la sociedad conyugal es un patrimonio autónomo, es decir, que los cónyuges y el patrimonio social son lo mismo durante la vigencia del régimen de sociedad de gananciales (Priori Posada, 2007, p. 486-487).

(7) Vid. una extensa lista de los contratos prohibidos y permitidos en el seno de la contratación entre cónyuges, en Varsi Rospigliosi (2012, p. 221-224). 
entre cónyuges no tiene nada que ver con el debilitamiento del matrimonio, más aún cuando la libertad de contratación es un principio constitucional protegido en el ordenamiento peruano, que exige interpretar los textos legales conforme a él. Sin embargo, también se señala que existen contratos que no pueden admitirse sin ponerse en riesgo el régimen patrimonial del matrimonio o sin crear serios peligros para los terceros que contraten con los cónyuges, pues se facilitarían las transferencias de bienes que podrían dejar a aquellos sin la garantía patrimonial para el cobro de sus créditos (2007a, p. 242-244).

Esto último parece presumir que los cónyuges actuarían de mala fe en caso de contar con plena libertad para contratar entre sí sobre sus bienes sociales, lo cual invertiría ese clásico principio civil que reza que "la buena fe se presume y la mala fe se prueba". En realidad, si de posibilidades hablamos, los cónyuges podrían actuar de buena o de mala fe bajo cualquier escenario, y si actúan de mala fe eso podría perjudicar a terceros; es decir, la ley debe prever los casos en los que los cónyuges actúan de mala fe y sancionarlos. Otra cosa es que la respuesta adecuada sea prohibir, en todo o en parte, la contratación entre cónyuges sobre bienes sociales, puesto que cabrían otras vías de protección de los intereses de terceros.

Lo antes anotado no muestra sino esa dicotomía argumental que apela a favor de la plena libertad de contratación entre cónyuges, pero que al mismo tiempo duda que esta sea la fórmula que deba implementarse en un orden civil como el peruano, el cual si bien ha sido evolutivo, respecto de las versiones de su regulación que aparecen en los CC 1852 y 1936, desde siempre se ha caracterizado por imponer a los cónyuges las reglas a que debe sujetarse su régimen patrimonial.

Entonces, ¿cuál es la finalidad perseguida por el artículo 312 CC? El propósito de la norma, según afirma la doctrina, es consolidar y proteger el patrimonio conyugal evitando su desmembración vía contractual (Gutiérrez Camacho, 2007b, p. 449), el enriquecimiento indebido de un cónyuge en perjuicio del otro, cualquier eventual fraude a los acreedores por la colusión entre cónyuges (De la Puente y Lavalle, 1983, p. 370-371), así como las ventas encubiertas o simuladas (Varsi Rospigliosi, 2012, p. 221). Si esto es así, el artículo 312 CC sería una suerte de mecanismo de control para suplir la ausencia de norma específica en el Código que sancione el actuar fraudulento del cónyuge que participa en la gestión de los bienes matrimoniales, y que capta la voluntad de su consorte mediante error o engaño para concluir el contrato, o de ambos cónyuges en connivencia. No estaría, entonces, pensado solo en función del interés de los terceros, sino también, y principalmente, del cónyuge débil. El artículo 312 CC tendría, en ese sentido, un carácter preventivo.

No obstante, existen algunas medidas en el CC que permitirían hacer frente a la actuación fraudulenta de uno de los cónyuges o de ambos, y que harían decaer los argumentos que hasta hoy defienden la necesidad de limitar la contratación entre cónyuges respecto de sus bienes sociales. En el caso peruano, el tercero acreedor bien podría proceder conforme a las reglas previstas para el fraude del acto jurídico (vid. artículos 195 a 200 CC), y en las que no voy a detenerme en este trabajo. En la misma medida, el cónyuge cuya manifestación de voluntad hubiese sido obtenida, por ejemplo, mediante error o engaño, bien podría accionar la anulabilidad por vicios del consentimiento (vid. artículos 221 y 222 CC), en los que tampoco voy a profundizar en esta ocasión.

\section{El mecanismo de «atribución voluntaria de ganancialidad a los bienes": ¿un desafío asumible en el Derecho peruano?}

La posibilidad de que los cónyuges puedan pactar una atribución de ganancialidad a determinados bienes constante matrimonio, es una cuestión que se fundamenta en los principios de autonomía patrimonial y de libertad de contratación entre cónyuges.

En algunos ordenamientos, como el español, junto con los criterios de determinación legal, en virtud de los cuales existen bienes que, adquiridos constante matrimonio, pasarán a tener inmediatamente la calidad de gananciales ${ }^{(8)}$ por disposición de la ley (artículo 1.347 CC esp.), está vigente el mecanismo de la atribución voluntaria de ganancialidad (artículo 1.355 CC esp.). Al amparo de esta atribución pueden los cónyuges, de común acuerdo, asignar la condición de ganancial a bienes que, en principio, habían de ser privativos, en cuanto adquiridos con fondos privativos de un

(8) En Derecho español se denomina bienes gananciales a los bienes que se hacen comunes de los cónyuges bajo un régimen de sociedad de gananciales (artículo1.347 CC esp.). 
cónyuge (artículo 1.346.3 CC esp.). Y esto es posible porque "la autonomía de la voluntad es la fuente de ganancialidad de los bienes en determinados casos" (Gutiérrez Barrenengoa, 2002, p. 36). Esto último se cimienta sobre la base del artículo 1.323 CC esp. que admite la libertad de pactos y contratos entre los cónyuges, como antes tuvimos oportunidad de ver.

La atribución voluntaria de carácter ganancial a los bienes es una de las fuentes de atribución de ganancialidad que recoge el CC esp. Por este mecanismo, como prevé el artículo 1.355.I CC esp., los cónyuges, de común acuerdo, podrán atribuir la condición de gananciales a los bienes que adquieran a título oneroso constante matrimonio, sin ser relevante, a este efecto, la procedencia del precio o contraprestación y la forma y plazos en que el precio se satisfaga. A su vez, la norma es clara al establecer que, si la adquisición de los bienes se hubiese llevado a cabo en forma conjunta y sin atribución de cuotas, se presumirá la voluntad favorable de ambos cónyuges al carácter ganancial de tales bienes (artículo 1.355.II CC esp.). Esta última, como se ve, es una presunción que favorece la atribución voluntaria de ganancialidad a concretos bienes cuando concurran las circunstancias previstas en la norma, pero siendo una presunción iuris tantum, puede ser desvirtuada mediante prueba en contra (Díez-Picazo y Gullón, 2003, p. 170; y, Martínez de Aguirre, 2016b, p. 260). Para enervar esta presunción de la voluntad común favorable a la ganancialidad, dice la doctrina jurisprudencial, el interesado debe probar que el precio pagado era privativo y que en el momento de la adquisición no hubo una voluntad común de integrar el bien en el patrimonio ganancial [STS 27 mayo 2019 (RJ 2019, 2143)].

Pues bien, esta posibilidad de los cónyuges de atribuir, de mutuo acuerdo, carácter ganancial a bienes que, conforme a los criterios de atribución legal, habían de ser privativos, como ya habrá podido advertir el lector, descansa ampliamente en la libertad de contratación entre cónyuges (artículo 1.323 CC esp.) (Peña Bernaldo de Quirós, 1989). La existencia del acuerdo se configura legalmente como un presupuesto de atribución de ganancialidad [STS 27 mayo 2019 (RJ 2019, 2143)]. Por ello, debe haber mutuo acuerdo entre cónyuges de reconocer la ganancialidad del bien, pues la voluntad de atribución de solo uno de ellos no es suficiente para atribuir la condición de ganancial a bienes privativos, de acuerdo con el criterio que ha fijado recientemente el Tribunal Supremo [STS 27 mayo 2019 (RJ 2019, 2143)].

Dependiendo de los fondos utilizados para la adquisición del bien y los criterios de determinación legal que debían operar para su calificación, la atribución voluntaria de ganancialidad puede tener varios escenarios en los que cabe detenernos para conocer exactamente cómo opera este mecanismo. En principio, el artículo 1.355 CC esp. faculta a los cónyuges para atribuir, de consuno, un carácter ganancial a bienes que, de no existir este común acuerdo, serían privativos por haber sido adquiridos con fondos privativos de un cónyuge (artículo 1.346.3 CC esp.). Adicionalmente, la STS 27 mayo 2019 (RJ 2019, 2143) señala que los cónyuges también pueden atribuir carácter ganancial, en su totalidad, a bienes adquiridos mediante precio en parte ganancial y en parte privativo (artículo 1.354 CC esp.). Si los fondos utilizados fueran gananciales, el bien adquirido sería ganancial por disposición del artículo 1.347.3 CC esp. y en este supuesto no haría falta la voluntad de los cónyuges para atribuir carácter ganancial al bien adquirido, salvo que no tuvieran la plena seguridad de que el dinero empleado proviene, en su totalidad, del caudal común.

De otra parte, el momento y la causa de la atribución voluntaria de ganancialidad determinarán las reglas a aplicarse al desplazamiento patrimonial, así como la generación de otras consecuencias jurídicas. Si el pacto se realiza al tiempo de la adquisición, el bien ingresará directamente en el patrimonio ganancial, quedando a salvo el derecho de reembolso (artículo 1.358 CC esp.). El negocio también quedará formalizado en los términos descritos cuando los cónyuges se limiten a expresar que la adquisición se hace "para la sociedad de gananciales" (Meco Tébar, 2020). Si el pacto fuera posterior a la adquisición, el mismo deberá encontrarse fundado en causa suficiente para que la transferencia del bien desde el patrimonio privativo en que se encuentra al patrimonio ganancial opere en forma efectiva (Peña Bernaldo de Quirós, 1989, p. 238-239).

Cabe volver a incidir en la importancia del acuerdo al que alude el artículo $1.355 \mathrm{CC}$ esp. Los acuerdos entre cónyuges operan en este precepto como un mecanismo para alterar la naturaleza de los bienes, pudiendo atribuir carácter ganancial a bienes privativos. En virtud de lo dispuesto por el artículo 1.355 CC esp., sin necesidad de apelar a figuras contractuales típicas, como la compraventa o la donación, el simple negocio o acuerdo atributivo de los cónyuges causará el desplazamiento de un concreto bien privativo al patrimonio común de los cónyuges, naciendo a causa de ello un derecho de reembolso a favor del patrimonio que sufra la disminución del activo, salvo que 
se manifieste ya satisfecho el reintegro del dinero o que se haga una renuncia expresa al mismo, quedando configurado el negocio atributivo en este último caso como uno de carácter gratuito (Garrido de Palma, 2001, p. 221-222).

Ahora bien, teniendo en cuenta la doctrina anterior, y habiéndose determinado que la prohibición del artículo 312 $\mathrm{CC}$ no afecta la posibilidad de los cónyuges de contratar entre sí sobre sus bienes propios, ¿estaría preparado el Derecho peruano para admitir, al menos en la práctica, el mecanismo de la "atribución voluntaria de ganancialidad"? Para dar respuesta a este interrogante voy a remitirme a un trabajo anterior, titulado "Pactos de atribución de ganancialidad o de privatividad a los bienes bajo un régimen de gananciales. Apuntes de Derecho español y peruano", publicado en Revista Boliviana de Derecho (2020, p. 488-498), cuyo principal argumento reseñaré brevemente.

La propia sistemática del régimen peruano de sociedad de gananciales impide de plano que se pueda alterar de común acuerdo entre cónyuges la naturaleza de los bienes sociales o comunes, pues aquellos se encuentran impedidos de contratar respecto de estos bienes. Pero tal limitación a los cónyuges de contratar entre sí no entraría en el ámbito de sus bienes propios. En consecuencia, no habría impedimento alguno para que los cónyuges atribuyeran de mutuo acuerdo carácter social a un bien propio, si bien no usando en estricto la figura de la atribución voluntaria de ganancialidad, porque no está prevista, sí a través de la modalidad de aportación al patrimonio social, que no está prohibida en el ordenamiento peruano, y que, de emplearse, debería hacerse constar en escritura pública e inscribirse en los Registros Públicos correspondientes para que sea oponible frente a terceros, o dejando operar sin más a la presunción de ganancialidad en el momento de la adquisición del bien (Santillán Santa Cruz, 2020, p. 496-497).

\section{Conclusiones}

Hagamos ahora, de manera sucinta, un balance final de todo lo expuesto. No hay razones para negar que el artículo 312 $\mathrm{CC}$, regulador de la "prohibición de contratos entre cónyuges", constituye una norma limitativa de la autonomía de la voluntad de los cónyuges y de su libertad para contratar entre sí respecto de determinados bienes. Argumento que sostengo firmemente aun cuando la contratación entre cónyuges no se encuentre totalmente proscrita en el Derecho peruano.

La clave para interpretar la prohibición del artículo 312 CC reside en la expresión "bienes de la sociedad" que forma parte de su contenido. Por bienes de la sociedad el citado precepto no ha querido referirse a todos los bienes que coexisten durante la vigencia de la sociedad de gananciales, aunque la dicción pudiera conducir al intérprete a este error. Una remisión al artículo 301 CC hace advertir que en el régimen de gananciales puede haber bienes propios y bienes de la sociedad. Esta norma emplea la misma terminología usada por el artículo 312 CC, siendo por tanto crucial para unificar el criterio y concluir que "bienes de la sociedad" no son todos los bienes que integran la sociedad de gananciales, pues el artículo $301 \mathrm{CC}$ distingue los bienes propios de cada cónyuge de los de la sociedad.

El término equivalente para "bienes de la sociedad" podemos encontrarlo en los artículos 310 y $315 \mathrm{CC}$. En estos preceptos se emplea la dicción de bienes sociales, permitiendo conducir de manera inequívoca el concepto de bienes de la sociedad a este último de bienes sociales. De no haberse reparado en esta lectura sistemática, quizá hasta podría prevalecer el confuso rótulo legal que encabeza el artículo 312 CC y conforme al cual hay, sin más, una "prohibición de contratar entre cónyuges" constante sociedad de gananciales.

El artículo 312 CC no prohíbe de plano la libertad de contratar de los cónyuges, sino solo la celebración de contratos entre sí sobre sus bienes sociales. Pueden contratar sobre sus bienes propios o de terceros y celebrar, incluso, cualesquiera otros contratos siempre que no involucren sus bienes sociales. No habiendo impedimento, por tanto, para que los cónyuges atribuyan de mutuo acuerdo carácter social a un bien propio usando la modalidad de aportación al patrimonio social, que no está prohibida y que necesitará estar inscrita para que pueda oponerse frente a terceros, o simplemente dejando operar a la presunción de ganancialidad en el momento de la adquisición del bien.

La prohibición del artículo 312 CC no es de aplicación en un régimen patrimonial de separación de patrimonios, sino únicamente en uno de sociedad de gananciales y solo dentro del ámbito ya determinado. La razón es muy simple. En una separación de patrimonios no hay bienes sociales, que es en relación con los cuales los cónyuges no pueden celebrar contratos entre sí. La regla del artículo 312 CC solo tiene sentido y es operable en un régimen de gananciales. 
La ratio legis de la norma objeto de análisis sería, a decir de la doctrina más predominante que se cita en el cuerpo de este trabajo, la necesidad de consolidar y proteger el patrimonio conyugal evitando su desmembración por la vía del contrato entre cónyuges, así como evitar el enriquecimiento indebido de uno de estos en perjuicio del otro y cualquier eventual fraude a los acreedores por la colusión entre cónyuges. No obstante, la experiencia comparada muestra que nada justifica restringir la libertad de contratación de los cónyuges cuando tales riesgos bien pueden paliarse con las normas generales de los contratos y del acto jurídico en general.

En definitiva, no habría razón para limitar la libertad de los cónyuges para contratar entre sí sobre sus bienes sociales, pues la posibilidad de realizar actos defraudatorios no es una que esté ínsita en la condición misma de los cónyuges, sino que pueden tener lugar como consecuencia de la actuación de cualquier sujeto, inmerso o no en una relación jurídico matrimonial. Las inhabilitaciones especiales que prohíben contratar entre sí, y en interés propio, a los cónyuges que han contraído matrimonio bajo un régimen de comunidad de bienes entrañarían injusticia, pues la condición de casados no comporta mayores peligros de lesión a los intereses de terceros o del propio cónyuge.

\section{Referencias bibliográficas}

Aguilar Llanos, Benjamín (2008). La Familia en el Código Civil peruano. Lima: Ediciones Legales.

Aguilar Ruiz, Leonor y Pizarro Moreno, Eugenio (2015). Régimen económico-matrimonial. La sociedad legal de gananciales. En: Eugenio Pizarro Moreno y Juan Pablo Pérez Velázquez (coord.). Derecho de familia (p. 103-141). Valencia: Tirant lo Blanch.

Blasco Gascó, Francisco (1997). Matrimonio y régimen económico matrimonial. En: A. M. López, V. L. Montés y E. Roca et al. Derecho de Familia (3ra ed., p. 185 y ss). Valencia: Tirant lo Blanch.

Castillo Freyre, Mario (2015). Concepto y formación del contrato. En: Código Civil. Decreto Legislativo 295. Edición Oficial (16ta ed., p. 443476). Lima: Ministerio de Justicia y Derechos Humanos.

Castro Pérez Treviño, Olga María (2010). La legislación peruana a propósito del régimen económico en las uniones matrimoniales y no matrimoniales. Revista Institucional de la Academia de la Magistratura, 9, p. 107-143.

Clemente Meoro, Mario (2012). El régimen económico matrimonial. En: Gema Díez-Picazo Giménez (coord.). Derecho de familia (p. 539 y ss). Pamplona: Aranzadi Thomson Reuters.

De la Puente y Lavalle, Manuel (1983). Estudios del contrato privado (Tomo I). Lima: Editorial Cuzco.

De los Mozos, José Luis (1982). Artículos 1.315 al 1.343 del Código civil. En Manuel Albaladejo (director). Comentarios al Código civil y Compilaciones forales. (Tomo XVIII., Vol. 1, 2da ed.). Madrid: Edersa.

Díez-Picazo, Luis y Gullón, Antonio (2003). Sistema de Derecho Civil. Derecho de familia. Derecho de sucesiones (Vol. IV, 8va ed.). Madrid: Tecnos.
García Cantero, Gabriel (2018). El régimen económico matrimonial primario. En: Víctor Manuel Garrido De Palma (direc.). Instituciones de Derecho privado. Familia (Vol. 3, Tomo IV, 2da ed., p. 19130). Pamplona: Civitas Thomson Reuters.

Garrido de Palma, Víctor (2001). La economía de la familia. Las capitulaciones matrimoniales y el régimen económico matrimonial. En: Juan Francisco Delgado de Miguel (coord.). Instituciones de Derecho privado. Familia (Vol. 1, Tomo IV, p. 199-268). Madrid: Civitas.

Gete-Alonso y Calera, Ma del Carmen (1990). La influencia del concepto de contrato en el Código civil. En: Centenario del Código civil (1889-1989) (Tomo I, p. 885-903). Madrid: Editorial Ramón Areces.

Gutiérrez Barrenengoa, Ainhoa (2002). La determinación voluntaria de la naturaleza ganancial o privativa de los bienes conyugales. Madrid: Dykinson.

Gutiérrez Camacho, Walter (2007a). Contratación entre cónyuges. En: Walter Gutiérrez Camacho (direc.). Código Civil comentado. Derecho de Familia (Primera parte) (Tomo II, 2da ed., p. 242243). Lima: Gaceta Jurídica.

(2007b). Formalidad del mutuo entre cónyuges. En: Walter Gutiérrez Camacho (direc.). Código Civil comentado. Contratos nominados (Primera parte) (Tomo VIII, 2da ed., p. 449 y ss). Lima: Gaceta Jurídica.

Lacruz, José Luis y Albaladejo, Manuel (1963). Derecho de familia. El matrimonio y su economía. Barcelona: Librería Bosch.

Martínez de Aguirre Aldaz, Carlos (2016a). La economía del matrimonio. Capitulaciones matrimoniales. En: Carlos Martínez de Aguirre Aldaz (coord.). Curso de Derecho Civil. Vol. IV. Derecho de Familia. (5ta ed., p. 223.248). Madrid: Edisofer.

(2016b). La sociedad de gananciales. En: Carlos Martínez de Aguirre Aldaz (coord.). Curso de Derecho Civil. Vol. IV. Derecho de Familia. (5ta ed., p. 249-294). Madrid: Edisofer.

Meco Tébar, Fabiola (2020). Los acuerdos entre cónyuges como mecanismo para atribuir la condición de ganancial a bienes privativos: los planes de pensiones. Comentario a la STS núm. 327/2019, de 6 de junio (RJ 2019, 1982). Revista Boliviana de Derecho, 29, p. 542-549.

Monfort Ferrero, María Jesús (2011). Del régimen económico matrimonial. En: Ana Cañizares Laso et al. (direc.). Código civil comentado. Libro IV: De las obligaciones y contratos. (Vol. III., p. 817 y ss). Navarra: Civitas - Thomson Reuters. 
Peña Bernaldo de Quirós, Manuel (1989). Derecho de Familia. Madrid: Universidad Complutense de Madrid.

Pérez Vallejo, Ana María (2002). El régimen matrimonial primario. En: Francisco Lledó Yagüe y Ramón Herrera Campos (direc.). Sistema de Derecho Civil. Derecho de Familia (p. 133-143). Madrid: Dykinson.

Plácido Vilcachagua, Alex (2016). La naturaleza de la intervención conyugal para disponer bienes sociales en la gestión patrimonial del régimen de sociedad de gananciales y su inconcurrencia como supuesto de ineficacia estructural del acto de disposición. Actualidad Civil, 19, p. 40-110.

Poder Ejecutivo del Perú. Decreto Legislativo $N^{\circ}$ 295. Código civil. Lima, 25 julio 1984. En: Portal Oficial del Sistema Peruano de Información
Jurídica del Ministerio de Justicia y Derechos Humanos. $16^{\mathrm{a}}$ ed. (marzo 2015). Disponible en <http://spij.minjus.gob.pe/notificacion/ guias/CODIGO-CIVIL.pdf> (última consulta: 2/5/2020).

Priori Posada, Giovanni (2007). Representación entre cónyuges. En: Walter Gutiérrez Camacho (direc.). Código Civil comentado. Título Preliminar. Derecho de las Personas. Acto Jurídico (Tomo I, 2da ed., p. 486-488). Lima: Gaceta Jurídica.

Roveda, Eduardo Guillermo (2015). Convenciones matrimoniales. En: Julio César Rivera y Graciela Medina (direc.). Código Civil y Comercial de la Nación comentado (Tomo II, p. 97-108). Buenos Aires: La Ley.

Santillán Santa Cruz, Romina (2020). Pactos de atribución de ganancialidad o de privatividad a los bienes bajo un régimen de gananciales. Apuntes de Derecho español y peruano. Revista Boliviana de Derecho, 29, p. 488-499.

Varsi Rospigliosi, Enrique (2012). Tratado de Derecho de familia. Derecho familiar patrimonial, relaciones económicas e instituciones supletorias y de amparo familiar (Tomo III). Lima: Gaceta Jurídica. 